\title{
Evaluation of the Nighttime Operation Impact on Liver Transplantation: A Meta-Analysis
}

\author{
Ziteng Zhang ${ }^{1 \#}$, Xiaoliang Zha ${ }^{2 \#}, \mathrm{Xian} \mathrm{He}^{3}$, \\ Mingbo Wang', Xin Zhao', Kun Zhang', Zhilong \\ Kang $^{1}$ and Bo Ren ${ }^{2 *}$ \\ ${ }^{1}$ Department of Hepato-Biliary Surgery, Southern \\ University of Science and Technology, China \\ ${ }^{2}$ Department of Anesthesiology, Southern University of \\ Science and Technology, China \\ ${ }^{3}$ Dali University, Fifth Medical Center of PLA General \\ Hospital, China \\ \#These two authors contributed equally to this work \\ *Correspondling author: Bo Ren, Department of \\ Anesthesiology, Shenzhen Third People's Hospital, \\ The Second Affiliated Hospital, Southern University of \\ Science and Technology, Shenzhen, 518055, China
}

Received: April 08, 2021; Accepted: April 26, 2021; Published: May 03, 2021

\begin{abstract}
Background: Liver transplant is frequently performed at night due to the unpredictability of organ procurement and reduction of Cold Ischemia Time (CIT). Previous study reported a doubled mortality Hazard Ratio (HR) of early death and increased postoperative complications in nighttime liver transplant. This study aims to evaluate the impact of nighttime operation on patients' survival and postoperative complications by using meta-analysis.
\end{abstract}

Methods: We performed a systematic review of the PubMed database and identified five eligible studies. Three time points (30 days, 90 days and 1 year) were explored in patients' survival by using pooled HR. Four types of postoperative complications (vascular, biliary tract, wound and primary graft non-function) were investigated by using pooled Odds Ratio (OR). Publication bias was also performed.

Results: Our study results were contradicting with the previous report and yielded no significant difference with a $\mathrm{HR}=0.98(95 \% \mathrm{Cl}=0.89-1.06)$ on 30 days, $\mathrm{HR}=1.12(95 \% \mathrm{Cl}=0.89-1.35)$ on 90 days and $\mathrm{HR}=1.07(95 \% \mathrm{Cl}=0.95-1.18)$ on 1 year in nighttime procedure. Consistent with the result of patients' survival, no significant result was found in postoperative complications evaluation as well. None of the four complications demonstrated significant result. And we failed to detect any significant publication bias.

Conclusions: Based on current evidence, nighttime liver transplantations do not degrade patients' survival or increase postoperative complications risk compared with daytime operations.

Keywords: Nighttime operation; Liver transplant; Meta-analysis

\section{Introduction}

Sleep deprivation and fatigue have long been accepted as a potential risk factor in surgical practice with various attempts trying to assess its effects on the outcomes of patients' safety. Lack of sleep may lead to changed attention concentration, impaired decision making capability, and the likelihood of mistakes [1]. It has been reported nighttime operation was significantly associated with higher surgical morbidity and mortality in many different studies $[2,3]$.

Liver Transplant (LT) has emerged in recent decades as a critical surgical option for patients with end stage liver disease, such as Acute Hepatic Failure (AHF), Hepatocellular Carcinoma (HCC), long-term untreated viral hepatitis and so on. Different from other surgical procedures, time of obtaining donation consent and retrieval of the organ are unpredictable and beyond the control of the surgical team. Furthermore, prolonged Cold Ischemia (CIT) has been pointed as an independent risk factor of graft failure. Any delay in the surgical intervention would increase cold ischemia time, thus increasing the risk of postoperative complications and risk of transplant failure [4]. All these factors make nighttime operation a regular procedure in liver transplant.

Liver transplant is a highly technical demanding operation and requires high quality surgical performance to ensure its success. With the help of standardized anesthetic, postoperative intensive care procedure and advanced immunosuppressive therapies, the incidence of non-surgery-related causes of graft failure have been dramatically reduced [5]. Therefore, different studies have explored the risk of sleep deprivation and fatigue on surgery performance in liver transplant by using different comparison patterns including weekday VS weekends, daytime VS nighttime and solitary VS consecutive transplantations [6-13].

Prior publication has summarized the risk of nighttime in liver transplantation with only narrative description of two studies [14]. The aim of this investigation was to systemically analysis the risk of nighttime procedure by selecting all related studies in order to provide comprehensive evidence about nighttime procedure risk.

\section{Materials and Methods}

This study was conducted in accordance to in accordance PRISMA (Preferred Reporting Items for Systematic Reviews and Meta-Analyses) Guidelines [15].

\section{Data sources}

We systematically searched PubMed database for relevant studies up to March 2021. The search key words combination of (surgeon fatigue or sleep deprivation or night time operation or nighttime operation or nighttime procedure or at night) and (liver operation or liver transplant or liver transplantation) were used. Furthermore, 
relevant references within the included studies were also evaluated to exclude any missing publications.

\section{Study selection}

The searched studies were evaluated based on the following criteria: (1) study that focused on comparing nighttime with daytime, other comparison design such as weekday with weekend was excluded (2) the operation type was restricted to liver transplantation and (3) the study design was retrospective cohort study. As for language restrictions, we limited the studies to those reported in English. The selection was conducted by two independent reviewers and consensus was achieved on eligible studies.

\section{Data extraction}

The data of the included studies was extracted. For each study, the following data was collected; first author, country where the study was performed, publication year and time category. Operative information was also collected into three parts including clinical characteristics of recipients, operative characteristics and donor characteristics.

Clinical characteristics of recipients include number of recipients, age, gender, Body Mass Index (BMI), the Model for End-Stage Liver Disease (MELD) and different cause percentage of indications. Operative characteristics consist of total time (h), cold ischemia time (h) and warm ischemia time ( $\mathrm{min}$ ). Donor characteristics comprised age, gender, BMI, percentage of donation after cardiac death (DCD $\%)$ and Donor Risk Index (DRI).

\section{Analyzed outcomes}

The outcomes investigated in this study were patients' survival and postoperative complications. Based on the data provided in the included studies, four time points in patients' survival were calculated, which were 7 days, 30 days, 90days and 1 year. Postoperative complications were collected from four categories which were vascular, biliary tract, wound and Primary Graft Non-Function (PNF). We pooled Hazard Risk (HR) and related 95\% Confidence Intervals (CI) for patients' survival, Odds Ratio (OR) and related 95\% CI for postoperative complications. In some studies which HR and 95\% CI was not directly provided, we collected the Kaplan-Meier curve in the publication and calculated the relevant $\mathrm{HR}$ and $95 \% \mathrm{CI}$ by using Engauge Digitizer version 4.1 and the practical methods for incorporating summary time-to-event data into meta-analysis [16].

\section{Statistical analyses}

Statistical analyses were performed by using STATA 12.0. Hazard Risk (HR) for patients' survival, odds ratio (OR) for postoperative complications were performed respectively. Heterogeneity was assessed with a $\chi^{2}$ or $\mathrm{I}^{2}$ test. Null heterogeneity between studies was defined when $\mathrm{I}^{2}<40 \%$; then we used a fixed effect model to calculate the ratio; otherwise a random effect model was applied. Additionally, publication bias was examined by Begg's and Egger's tests. If $\mathrm{p}$ value was $<0.05$, publication bias was statistically significant; otherwise, it was considered no publication bias.

\section{Results}

\section{Patients' characteristics of the included studies}

The process of study selection was shown in Figure 1. The initial

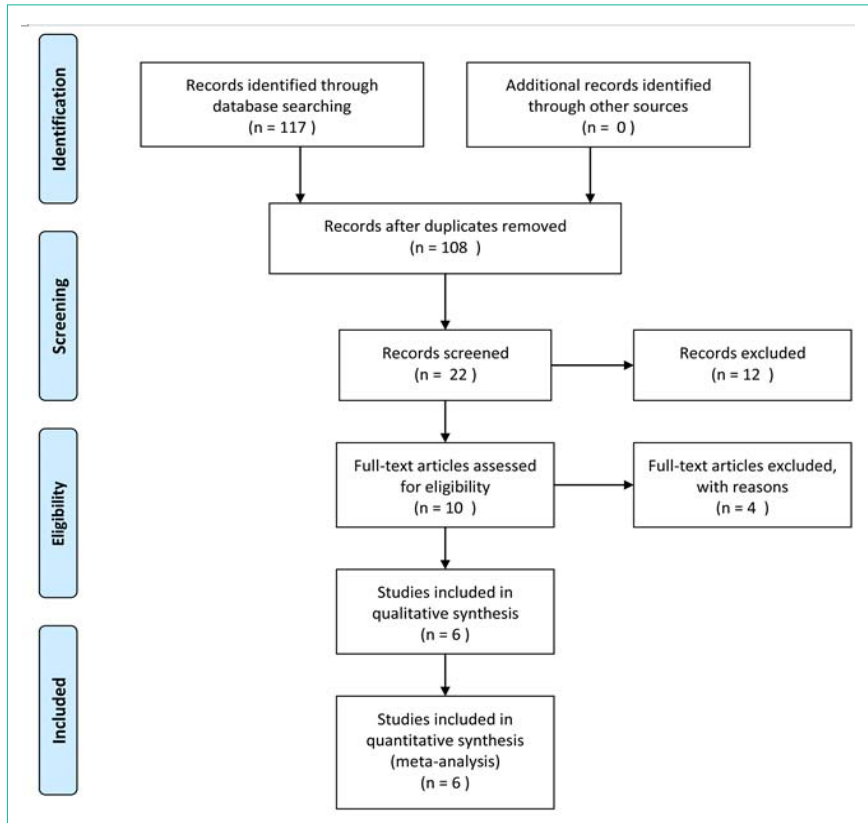

Figure 1: The flow chart of the selection of eligible studies.

research retrieved 117 records. After the removal of duplicates and reading the abstract, 22 publications were left. Then, full text was assessed to identify the eligible studies. At last, 6 studies met all the criteria and were included [9-13,17].

Among them, three studies were performed in the USA, two studies were in the Europe and one study was conducted in China. The result of three studies was from single-center investigations $[9,11,17]$. The other three studies were multi-center results by using either the United Network for Organ Sharing database (UNOS) in the USA or the UK Transplant Registry database $[10,12,13]$. The detailed overview of each study was in Table 1.

\section{Impact of nighttime liver transplantation on patients' survival}

Based on the data provided in each study, we selected three time points to assess patients' survival, including 30 days, 90 days and 1 year. Previous study by B. E. Lonze and his colleges reported a doubled risk increase of early death $(\mathrm{HR}=2.8 ; 95 \% \mathrm{CI}=1.2-7.0 ; \mathrm{P}$ $=0.023$ ) in nighttime liver transplant [11]. In contrast, our study failed to find any survival difference between night time and daytime operations within 30 days $\mathrm{HR}=0.98$ (95\% CI=0.89-1.06). The forest plot was shown in Figure 2.

Similarly, in the result of 90 days, four studies were included and there was no significant difference was found HR=1.12 (95\% $\mathrm{CI}=0.89-1.35)$ as shown in Figure 3. Similar outcome was also found in the result of 1 year survival chance $(\mathrm{HR}=1.07$ (95\% CI=0.95-1.18, Figure 3). All the results were illustrated in Table 2.

\section{Impact of nighttime liver transplantation on postoperative complications}

The postoperative complications analyses were also described. In this investigation, we included four types of postoperative complications and relevant Odds Ratios (OR) were calculated. 
Table 1: Characteristics of the included studies.

\begin{tabular}{|c|c|c|c|c|c|c|c|c|c|c|c|c|c|c|c|c|c|c|c|c|c|c|c|c|}
\hline \multirow[b]{3}{*}{ Ref } & \multirow{3}{*}{$\begin{array}{l}\text { First author } \\
\text { Country } \\
\text { Year }\end{array}$} & \multirow[b]{3}{*}{$\begin{array}{c}\text { Time } \\
\text { category }\end{array}$} & \multicolumn{14}{|c|}{ Clinical characteristics of recipients } & \multirow{2}{*}{\multicolumn{3}{|c|}{ Operative characteristics }} & \multicolumn{5}{|c|}{ Donor characteristics } \\
\hline & & & Number & & & & & & & & & Indicat & tion (\%) & & & & & & & & & & & \\
\hline & & & $\begin{array}{c}\text { Of } \\
\text { recipients }\end{array}$ & age & BMI & MELD & $\begin{array}{l}\text { Male } \\
(\%)\end{array}$ & $\mathrm{HCC}$ & ALF & $\begin{array}{c}\text { Viral } \\
\text { hepatitis }\end{array}$ & $\begin{array}{l}\text { PBCl } \\
\text { PSCl } \\
\text { SSC }\end{array}$ & AlH & $\begin{array}{c}\text { NASHI } \\
\text { cryptogenic }\end{array}$ & PLD & $\begin{array}{l}\text { Alcoholic } \\
\text { cirrhosis }\end{array}$ & others & $\begin{array}{c}\text { Total time } \\
\text { (h) }\end{array}$ & $\begin{array}{l}\text { ischemia } \\
\text { time (h) }\end{array}$ & $\begin{array}{c}\text { Warm ischemia } \\
\text { time (min) }\end{array}$ & age & $\begin{array}{c}\text { Male } \\
(\%)\end{array}$ & BMI & $\begin{array}{l}\text { DCD } \\
(\%)\end{array}$ & DRI \\
\hline \multirow{2}{*}{11} & \multirow{2}{*}{$\begin{array}{l}\text { Lonze BE, } \\
\text { et al. } \\
\text { USA. } \\
2010\end{array}$} & \begin{tabular}{|c|} 
Day time: \\
7 AM-7 \\
PM \\
\end{tabular} & 388 & $50.7 \pm 9.6$ & $27.4 \pm 5.1$ & $\mid 20.6 \pm 8.4$ & 69.9 & - & - & 45.1 & - & - & - & - & 19.1 & - & $9.1 \pm 3.3$ & $9.3 \pm 2.3$ & - & $45.7 \pm 18.9$ & - & $25.4 \pm 4.8$ & 5.7 & $1.6 \pm 0.5$ \\
\hline & & $\begin{array}{c}\text { Night time: } \\
7 \text { PM-7 } \\
\text { AM }\end{array}$ & 190 & $52.3 \pm 9.2$ & $27.2 \pm 5.1$ & $21.0 \pm 8.1$ & 63.2 & - & - & 42.1 & - & - & - & - & 17.4 & - & $9.6 \pm 4.2$ & $9.1 \pm 2.2$ & - & $44.0 \pm 17.2$ & - & $25.0 \pm 4.4$ & 6.8 & $1.7 \pm 0.5$ \\
\hline \multirow{2}{*}{12} & \multirow{2}{*}{$\begin{array}{l}\text { Orman ES, } \\
\text { et al. } \\
\text { USA } \\
2012\end{array}$} & \begin{tabular}{|c|} 
Daytime: \\
7 AM-7 \\
PM \\
\end{tabular} & 51543 & $50.7 \pm 11$ & - & $21.2 \pm 10$ & 64 & - & 6 & 34 & - & - & 11 & & 14 & 36 & - & $8(6-10.5)$ & $46(36-60)$ & $38.3 \pm 17$ & 60 & - & 2 & - \\
\hline & & \begin{tabular}{|c|} 
Night time: \\
7 PM-7 \\
AM \\
\end{tabular} & 31143 & $51.1 \pm 11$ & - & $21.3 \pm 9$ & 64 & - & 7 & 33 & - & - & 11 & - & 13 & 36 & - & $7(5.2-9.4)$ & $45(35-60)$ & $38.1 \pm 17$ & 61 & - & 4 & - \\
\hline \multirow{2}{*}{9} & \multirow{2}{*}{$\begin{array}{l}\text { Becker F, } \\
\text { et al. } \\
\text { Germany } \\
2019\end{array}$} & \begin{tabular}{|c|} 
Daytime: \\
6 AM-8 \\
PM \\
\end{tabular} & 154 & $51.3 \pm 12.1$ & $\begin{array}{c}25.7 \\
(22.8-29.4)\end{array}$ & $22.1 \pm 12.4$ & 63 & 20.8 & 12.3 & 14.3 & 10.4 & - & - & 4.5 & 14.3 & 23.4 & - & $10.1 \pm 2.6$ & $40.6 \pm 9.3$ & $49.4 \pm 14.7$ & 53.9 & $\begin{array}{c}25 \\
(23.7- \\
27.7)\end{array}$ & - & $\begin{array}{c}1.728 \pm \\
0.368\end{array}$ \\
\hline & & $\begin{array}{c}\text { Night time: } \\
\text { 8 PM-6 } \\
\text { AM }\end{array}$ & 196 & $53.3 \pm 11.0$ & $\begin{array}{c}25.4 \\
(22.9-29.5)\end{array}$ & $22.3 \pm 12.2$ & 65.3 & 25.5 & 13.2 & 12.8 & 10.7 & - & - & 2 & 18.4 & 17.4 & - & $10.0 \pm 2.6$ & $41.2 \pm 9.4$ & $54.5 \pm 14.7$ & 57.1 & $\begin{array}{l}25.7 \\
(23.7- \\
28.9)\end{array}$ & - & $\begin{array}{c}1.820 \pm \\
0.340\end{array}$ \\
\hline \multirow{2}{*}{13} & \multirow{2}{*}{$\begin{array}{c}\text { Thuluvath PJ, } \\
\text { et al. } \\
\text { USA } \\
2019\end{array}$} & \begin{tabular}{|c|} 
Daytime: \\
6 AM-8 \\
PM \\
\end{tabular} & 41546 & $52.2 \pm 10.9$ & $28.4 \pm 5.9$ & $24.6 \pm 9.9$ & 61.8 & - & - & 34.5 & 10.9 & 3.4 & 16.1 & - & 17.6 & 17.5 & - & - & - & - & - & - & - & $1.82 \pm 0.45$ \\
\hline & & $\begin{array}{c}\text { Night time: } \\
\text { 8 PM-6 } \\
\text { AM }\end{array}$ & 4434 & $52.5 \pm 10.6$ & $28.5 \pm 5.9$ & $25.0 \pm 9.8$ & 63 & - & - & 34.9 & 9.3 & 3.3 & 18.1 & - & $17 . .7$ & 16.7 & - & - & - & - & - & - & - & $1.80 \pm 0.43$ \\
\hline \multirow{2}{*}{10} & \multirow{2}{*}{$\begin{array}{c}\text { Halliday N, } \\
\text { et al. } \\
\text { UK } \\
2019\end{array}$} & \begin{tabular}{|c|} 
Daytime: \\
7 AM-7 \\
PM \\
\end{tabular} & 2715 & - & - & - & - & - & - & - & - & - & - & - & - & - & - & - & - & - & - & - & - & - \\
\hline & & $\begin{array}{c}\text { Night time: } \\
7 \text { PM-7 } \\
\text { AM }\end{array}$ & 6101 & - & - & - & - & - & - & - & - & - & - & - & - & - & - & - & - & - & - & - & - & - \\
\hline \multirow{2}{*}{17} & \multirow{2}{*}{$\begin{array}{l}\text { Sheng-Sheng } \\
\text { Ren, et al. } \\
\text { China } \\
2019\end{array}$} & \begin{tabular}{|c|} 
Daytime: \\
8 AM-2 \\
PM \\
\end{tabular} & 102 & $47.85 \pm 10.35$ & $23.31 \pm 2.96$ & - & 87.3 & - & - & - & - & - & - & - & - & - & $8.26 \pm 1.69$ & $7.21 \pm 3.93$ & - & $36.86 \pm 15.87$ & & & & \\
\hline & & $\begin{array}{c}\text { Night time: } \\
8 \text { PM-2 } \\
\text { AM }\end{array}$ & 45 & $49.13 \pm 8.14$ & $22.92 \pm 2.91$ & - & 84.4 & - & - & - & - & - & - & - & - & - & $8.90 \pm 1.65$ & $9.35 \pm 5.03$ & - & $37.76 \pm 12.28$ & & & & \\
\hline
\end{tabular}

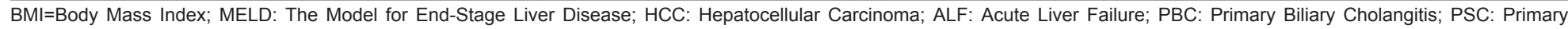

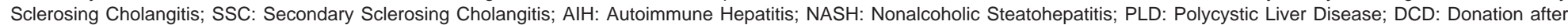
Cardiac Death; DRI: Donor Risk Index.

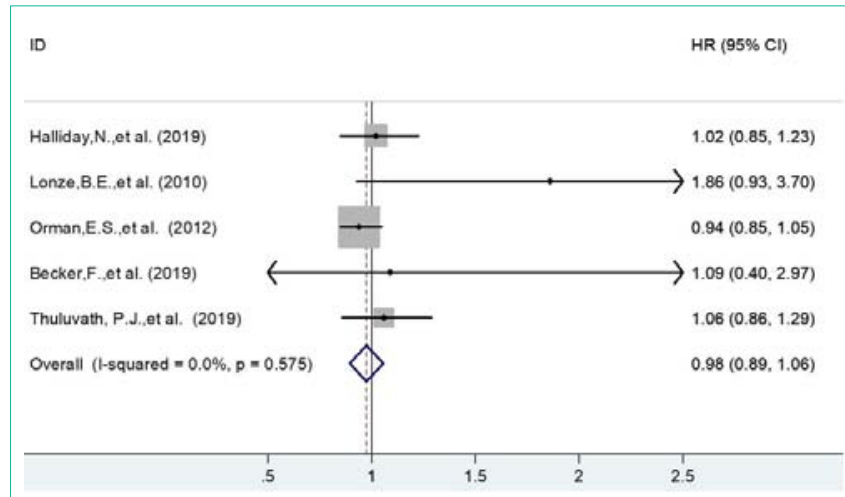

Figure 2: The forest plot of patients' survival on 30 days.

Vascular complications included thrombosis and stenosis in hepatic artery and portal vein [18]. Three studies were included and the calculated OR showed no increase in the risk of nighttime operations $(\mathrm{OR}=1.13,95 \% \mathrm{CI}=0.92-1.39$, Table 3$)$.

Biliary tract complication is the most common complication in liver transplant [19]. There was no difference in biliary tract complication rates at night when three studies were analyzed together $(\mathrm{OR}=1.00,95 \% \mathrm{CI}=0.80-1.25$, Table 3$)$.

For the complication of wound and Primary Graft Non-Function (PNF), each of them contained two studies, similar to above result, there were no significant results when comparing nighttime and daytime $(\mathrm{OR}=0.92,95 \% \mathrm{CI}=0.62-1.36 ; \mathrm{OR}=1.13,95 \% \mathrm{CI}=0.92-1.37$, respectively, Table 3$)$.

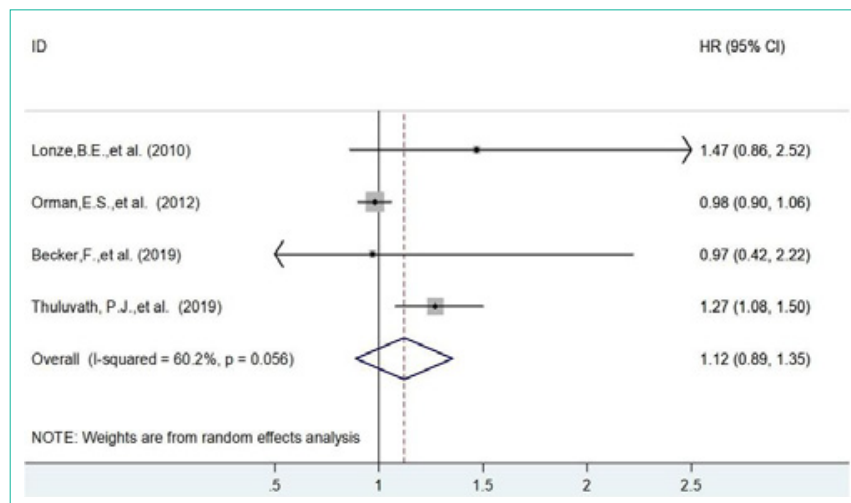

Figure 3: The forest plot of patients' survival on 90 days.

\section{Publications bias}

This investigation also assessed the publication bias by using Begg's funnelplots and Egger's test. Because of limited number in postoperative complication, publication bias was only conducted in patients' survival. All three time points were evaluated and none of the result was found to be significant. The detailed results were shown in Table 4.

\section{Discussion}

Over the past decade, a drive to identify and reduce the potential surgical interventions risk carried out at night has been initiated, as well as a drive to reduce the workload of surgeons. Many studies have shown that patients who had surgical procedures outside regular working hours have worse outcomes, such as myocardial 
Table 2: Summary of patients' survival.

\begin{tabular}{|c|c|c|c|c|c|c|}
\hline \multirow{2}{*}{ Patient survival } & \multirow{2}{*}{ No. of studies } & \multirow{2}{*}{ HR $(95 \% \mathrm{Cl})$} & \multicolumn{3}{|c|}{ Test for heterogeneity } & \multirow{2}{*}{ Model } \\
\hline & & & $x^{2}$ & $P$ & $\mathrm{I}^{2}(\%)$ & \\
\hline 30 days & 5 & $0.98(0.89-1.06)$ & 2.9 & 0.58 & $0.00 \%$ & $\mathrm{~F}$ \\
\hline 90 days & 4 & $1.12(0.89-1.35)$ & 7.55 & 0.06 & $60.20 \%$ & $\mathrm{R}$ \\
\hline 1 year & 5 & $1.07(0.95-1.18)$ & 8.92 & 0.06 & $55.20 \%$ & $\mathrm{R}$ \\
\hline
\end{tabular}

HR: Hazard Ratio, Cl: Confidence Intervals.

Table 3: Summary of postoperative complications.

\begin{tabular}{|c|c|c|c|c|c|c|c|c|}
\hline \multirow{2}{*}{ Complications } & \multirow{2}{*}{ No. of studies } & \multicolumn{3}{|c|}{ Test for association } & \multicolumn{3}{|c|}{ Test for heterogeneity } & \multirow{2}{*}{ Model } \\
\hline & & OR $(95 \% \mathrm{Cl})$ & z & $\mathbf{P}$ & $\mathrm{X}^{2}$ & $\mathbf{P}$ & $\mathrm{I}^{2}(\%)$ & \\
\hline Vascular & 4 & $1.13(0.92-1.39)$ & 1.17 & 0.24 & 3.55 & 0.32 & $15.70 \%$ & $\mathrm{~F}$ \\
\hline Biliary tract & 4 & $1.00(0.80-1.25)$ & 0 & 0.99 & 0.89 & 0.83 & $0.00 \%$ & $\mathrm{~F}$ \\
\hline Wound & 3 & $0.92(0.62-1.36)$ & 0.42 & 0.68 & 1.65 & 0.44 & $0.00 \%$ & $\mathrm{~F}$ \\
\hline PNF & 3 & $1.13(0.92-1.37)$ & 1.24 & 0.21 & 1.31 & 0.52 & $0.00 \%$ & $\mathrm{~F}$ \\
\hline
\end{tabular}

OR: Odds Ratio, Cl: Confidence Intervals, PNF: Primary Graft Non-Function

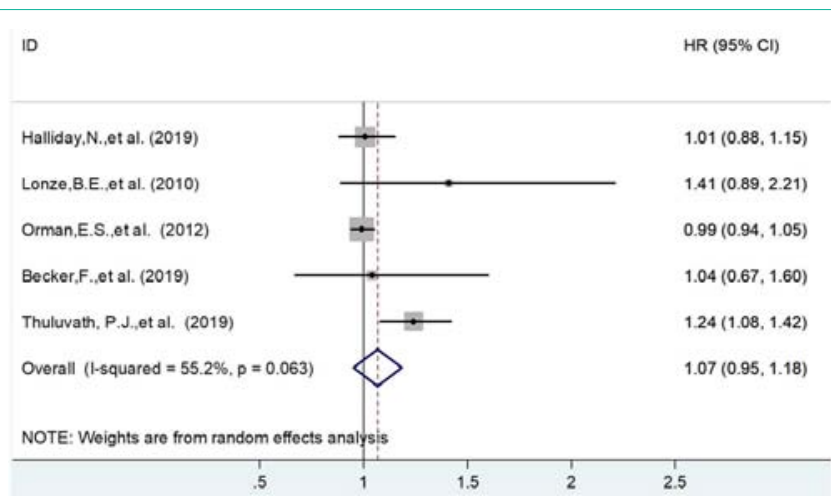

Figure 4: The forest plot of patients' survival on 1 year.

infarction, pulmonary embolism and gastrointestinal bleeding [20$22]$. Therefore, most complex surgical procedures are done electively except for emergency surgical procedures. Even so, complication rate has been reported to be significantly higher with nighttime operation such as colorectal, laparoscopic surgeries [23,24].

Liver transplantation was usually defined as semi-elective surgery, because the time to start the transplant was depended on various factors, such as organ retrieval and procurement, the availability of experienced anesthetist, and the recipient status [25]. The impact of nighttime or weekend surgeries on liver transplantation had been previously examined with conflicting results. For instance, Lonze et al.'s study reported a doubled risk increase $(\mathrm{HR}=2.8$; $95 \% \mathrm{CI}=1.2-7.0 ; \mathrm{P}=0.023)$ in early death when the liver transplant was performed at night [11]. Conversely, Halliday N. et al. found a possible reduction in the hazard ratio of early graft failure and long-term transplant failure associated with weekend transplant [180]). In the latest study conducted in China mainland, researchers reported more intraoperative complications and blood loss in nighttime transplantation patients [17]. This discordant result urged us to systematically assess the risk of nighttime operation in liver transplantation.

In this investigation, six studies were included and a total number of 138,557 patients were included to analysis the association.
Table 4: Publication bias accessed by Begg's and Egger's tests.

\begin{tabular}{|c|c|c|}
\hline Items & Begg's test & Egger's test \\
\hline 30 days & 0.6 & 0.5 \\
\hline 90 days & 0.5 & 0.95 \\
\hline 1 year & 0.62 & 0.87 \\
\hline
\end{tabular}

According to our study, the outcomes of liver transplant surgeries were not affected whether they were performed at nighttime or daytime. We also investigated the effect of nighttime operation on postoperative complication and failed to detect any significant result. To our best knowledge, this is the first meta-analysis of the available evidence comparing the outcome of the liver transplantation in nighttime and daytime. These results reassured us the confidence of safety regardless of the time to perform surgery.

In term of the significant result reported, one possible explanation for this discrepancy would be they were from single-center reports with limited center experience and center volume [11,17]. In contrast, large studies using United Network for Organ Sharing (UNOS) database or the UK Transplant Registry Database showed that patient survival after liver transplantation was not influenced by nighttime surgery $[10,12,13]$. In other organ transplants, such thoracic organ, studies based on UNOS also demonstrated no difference between nighttime and daytime procedure on the results of patients' survival [26].

Moreover, Lonze's result was based the transplantation cases collected from 1995 to 2008, new surgical techniques and antirejection therapies have been developed which to some extent could narrow the possible gap between daytime and nighttime operation [11]. In nowadays, standardized anesthetic, postoperative intensive care procedure and advanced immunosuppressive therapies also reduced the potential risk of nighttime operation and have made liver transplantation surgery safely to perform throughout the year. Our investigation with 6 studies included provided a strong evidence to assure this conclusion compared with the previous systematic review [14].

Nevertheless, the influence of sleep deprivation and fatigue is of no doubt. In police officers, night shift work was associated with a higher 
injury risk [27]. For driving, the effects of fatigue are comparable to alcohol intake [28]. However, in nighttime surgery, especially in liver transplantation, the situation was much more sophisticated. During nighttime procedures, senior surgeons would perform the procedure himself rather than training young surgeons and extract carefulness would be expected due to the late operation start time. Furthermore, overnight procedure allows more concentration and less distraction from outside environment [29]. These might be the possible explanations why some studies found less technical failure off regular work time [10,30].

After thorough consideration, it is not difficult to argue that the core for this issue is not the time point itself but the availability of adequately trained, fully physiological prepared surgeons and support team during nighttime procedure. Although the seniority of transplantation team (surgeons, anesthesiologists, nurses and intensive care staff) could not be quantitatively collected, many studies emphasized the importance of highly experienced transplant team and specialized over-night on call schedule $[17,9,10,12,13]$. Too much workload within a short period of time would definitely degrade operation quality and increase the postoperative complication risk. On the contrary, highly experienced and well prepared transplant team would guarantee patient safety regardless of the operation start time. So, it is crucial for a liver transplant center to establish solid patient safety mechanisms to ensure the transplant quality remain continuously consistent.

There are also some limitations in this study. First, different defining time stratification schemes were applied in selected studies. The characteristics of the included patients and operations were also different among studies. Secondly, the number of included studies was limited and all of them were conducted in the USA and the Europe. We are looking forward to more similar high-quality studies in other transplant centers, such as Asian regions.

\section{Conclusion}

There was no evidence that nighttime liver transplantations would degrade patients' survival or increase postoperative complications risk compared with daytime operations.

\section{Declarations}

\section{Consent for publication}

All authors agree on the submission of the manuscript.

\section{Funding}

There was a funding from Shenzhen Fund for Guangdong Provincial High-level Clinical Key Specialties (No.SZGSP010) for this study.

\section{Acknowledgement}

We would like to express our gratitude to Prof. Han Bao from Department of statistics, Harbin Medical University for her kindly help in the methodology of the manuscript.

\section{Conflict of Interest}

This manuscript is a previously unpublished work and no other submission or publication will be made. All of the authors participated in the study and they have agreed to the content of the manuscript.
Besides, each author certifies that he or she has no actual or potential commercial personal or any other associations within five years of the beginning the work that might pose a conflict of interest related to this work

\section{Highlights}

- This meta-analysis explored the risk of nighttime operation on liver transplantation.

- Nighttime operation has no major impact on patients' survival in liver transplant.

- Safety mechanism should be established to ensure nighttime operation quality.

\section{References}

1. Sugden C, Athanasiou T, Darzi A. What are the effects of sleep deprivation and fatigue in surgical practice? Seminars in thoracic and cardiovascular surgery. 2012; 24: 166-175

2. Drake FT, Mottey NE, Castelli AA, Florence MG, Johnson MG, Steele SR, et al. Time-of-day and appendicitis: Impact on management and outcomes. Surgery. 2017; 161: 405-414.

3. Sugunes N, Bichmann A, Biernath N, Peters R, Budde K, Liefeldt L, et al. Analysis of the Effects of Day-Time vs. Night-Time Surgery on Renal Transplant Patient Outcomes. Journal of clinical medicine. 2019; 8: 1051.

4. Freitas ACT, Matos DMN, Milsted JAT, Coelho JCU. Effects of Cold Ischemia Time on Hepatic Allograft Function. Arquivos brasileiros de cirurgia digestiva: $A B C D=$ Brazilian archives of digestive surgery. 2017; 30: 239-243.

5. De Simone P, Fagiuoli S, Cescon M, De Carlis L, Tisone G, Volpes R, et al. Use of Everolimus in Liver Transplantation: Recommendations From a Working Group. Transplantation. 2017; 101: 239-251.

6. Bosca A, Montalva EM, Maupoey J, Arguelles B, Navio A, Calatayud D, et al. Does Surgeon Fatigue Influence the Results of Liver Transplantation? Transplantation proceedings. 2019; 51: 67-70

7. Halldorson JB, Bakthavatsalam R, Reyes JD, Perkins JD. The impact of consecutive operations on survival after liver transplantation. Liver transplantation: official publication of the American Association for the Study of Liver Diseases and the International Liver Transplantation Society. 2009; 15: $907-914$

8. Khaderi S, Nguyen N, Guitea J, Cotton R, O'Mahony C, Goss J. Association of Operative Start Time with Surgical Complications in Orthotopic Liver Transplantation (OLT).: Abstract\# C1963. Transplantation. 2014; 98: 749.

9. Becker F, Voss T, Mohr A, Mehdorn AS, Schutte-Nutgen K, Reuter S, et al. Impact of nighttime procedures on outcomes after liver transplantation. PloS one. 2019; 14: e0220124.

10. Halliday N, Martin K, Collett D, Allen E, Thorburn D. Is liver transplantation 'out-of-hours' non-inferior to 'in-hours' transplantation? A retrospective analysis of the UK Transplant Registry. BMJ open. 2019; 9: e024917.

11. Lonze BE, Parsikia A, Feyssa EL, Khanmoradi K, Araya VR, Zaki RF, et al. Operative start times and complications after liver transplantation. American journal of transplantation: official journal of the American Society of Transplantation and the American Society of Transplant Surgeons. 2010; 10: $1842-1849$

12. Orman ES, Hayashi PH, Dellon ES, Gerber DA, Barritt AS. Impact of nighttime and weekend liver transplants on graft and patient outcomes. Liver transplantation: official publication of the American Association for the Study of Liver Diseases and the International Liver Transplantation Society. 2012; 18: 558-565.

13. Thuluvath PJ, Amjad W, Savva Y, Thuluvath AJ, LaMattina J. Survival Outcomes Are Not Affected When Liver Transplant Surgery Is Done at Night, During Weekends, or Summer Months. Transplantation direct. 2019; 5: e449.

14. Hendrikx J, Van Raemdonck D, Pirenne J, Fieuws S, Rex S. Outcome of 
transplantation performed outside the regular working hours: A systematic review and meta-analysis of the literature. Transplantation reviews (Orlando, Fla). 2018; 32: 168-177.

15. Liberati A, Altman DG, Tetzlaff J, Mulrow C, Gøtzsche PC, loannidis JP, et al The PRISMA statement for reporting systematic reviews and meta-analyses of studies that evaluate healthcare interventions: explanation and elaboration. BMJ (Clinical research ed). 2009; 339: b2700.

16. Tierney JF, Stewart LA, Ghersi D, Burdett S, Sydes MR. Practical methods for incorporating summary time-to-event data into meta-analysis. Trials. 2007; 8: 16.

17. Ren SS, Xu LL, Wang P, Li L, Hu YT, Xu MQ, et al. Circadian Rhythms Have Effects on Surgical Outcomes of Liver Transplantation for Patients With Hepatocellular Carcinoma: A Retrospective Analysis of 147 Cases in a Single Center. Transplantation proceedings. 2019; 51: 1913-1919.

18. Ma L, Lu Q, Luo Y. Vascular complications after adult living donor liver transplantation: Evaluation with ultrasonography. World journal of gastroenterology. 2016; 22: 1617-1626.

19. Nemes B, Gaman G, Doros A. Biliary complications after liver transplantation Expert review of gastroenterology \& hepatology. 2015; 9: 447-466.

20. Lin X, Green JC, Xian H, Cai M, Skrzypek J, Tao H. Holiday and weekend effects on mortality for acute myocardial infarction in Shanxi, China: a crosssectional study. International journal of public health. 2020; 65: 847-857.

21. Shih PC, Liu SJ, Li ST, Chiu AC, Wang PC, Liu LY. Weekend effect in upper gastrointestinal bleeding: a systematic review and meta-analysis. PeerJ. 2018; 6: e4248.

22. Manfredini R, Fabbian F. Pulmonary embolism, mortality, 'weekend effect' and gender: what do we know? Future cardiology. 2018; 14: 9-13.
23. Fernandes S, Carvalho AF, Rodrigues AJ, Costa P, Sanz M, Goulart A, et al. Day and night surgery: is there any influence in the patient postoperative period of urgent colorectal intervention? International journal of colorectal disease. 2016; 31: 525-533.

24. Geraedts ACM, Sosef MN, Greve JWM, de Jong MC. Is Nighttime Really Not the Right Time for a Laparoscopic Cholecystectomy? Canadian journal of gastroenterology \& hepatology. 2018; 2018: 6076948.

25. Neuberger J. Surgery: Day or night--does the time of liver transplantation matter? Nature reviews Gastroenterology \& hepatology. 2010; 7: 596-597.

26. George TJ, Arnaoutakis GJ, Merlo CA, Kemp CD, Baumgartner WA, Conte $\mathrm{JV}$, et al. Association of operative time of day with outcomes after thoracic organ transplant. Jama. 2011; 305: 2193-2199.

27. Violanti JM, Fekedulegn D, Andrew ME, Charles LE, Hartley TA, Vila B, et al Shift work and the incidence of injury among police officers. American journal of industrial medicine. 2012; 55: 217-227.

28. Makowiec-Dabrowska T, Bortkiewicz A, Siedlecka J, Gadzicka E. [Effect of fatigue on the fitness to drive]. Medycyna pracy. 2011; 62: 281-290.

29. McCurdie T, Sanderson P, Aitken LM. Applying social network analysis to the examination of interruptions in healthcare. Applied ergonomics. 2018; 67 : $50-60$.

30. Brunschot DM, Hoitsma AJ, van der Jagt MF, d'Ancona FC, Donders RA, van Laarhoven CJ, et al. Nighttime kidney transplantation is associated with less pure technical graft failure. World journal of urology. 2016; 34: 955-961. 